\title{
A demonstração experimental investigativa na EJA: pequenas mudanças grandes diferenças
}

The experimental investigative demonstration at EJA: small changes, big differences

La demostración experimental de investigación en EJA: pequeños cambios, grandes diferencias

Recebido: 14/07/2020 | Revisado: 16/07/2020 | Aceito: 22/07/2020 | Publicado: 06/08/2020

Milton Batista Ferreira Junior

ORCID: https://orcid.org/0000-0002-8272-3610

Universidade de Rio Verde, Brasil

E-mail: Milton.junior@unirv.edu.br

Vinícius Alexandre de Castro

ORCID: https://orcid.org/0000-0003-4273-4793

Universidade de Rio Verde, Brasil

E-mail: vinicius.castro@unirv.edu.br

Michael Dowglas de Gois Silva

ORCID: https://orcid.org/0000-0001-5162-9368

Universidade de Rio Verde, Brasil

E-mail: michael@unirv.edu.br

\section{Resumo}

Os documentos oficiais que estabelecem as diretrizes metodológicas da Educação de Jovens e Adultos (EJA) priorizam estratégias que valorizam o conhecimento dos educandos a partir de práticas de ensino permeadas pelo diálogo. Embora exista tais orientações, parece haver um distanciamento entre elas e o que é vivido nas escolas. Tal distanciamento é evidenciado ao se deparar com professores frustrados com suas práticas ao perceberem que elas não despertam o interesse de seus alunos pelo que se pretende ensinar. Este trabalho surge de uma visita de dois professores universitários a um colégio da rede pública para divulgarem um projeto de extensão universitária. Após esse primeiro contato, um professor de Física do colégio solicita auxílio dos professores universitários para que o ajudasse tornar sua aula mais atrativa para sua turma de EJA. Dessa maneira, foi realizado um trabalho entre professores pesquisadores 
(universitários) e professor parceiro no sentido de esclarecer os pressupostos teóricos e metodológicos do Ensino de Ciências na EJA com a abordagem do Ensino de Ciências por Investigação. Uma aula sobre Refração da Luz foi elaborada e ministrada pelo professor parceiro utilizando materiais disponíveis na escola e alterando a maneira de condução da aula. Para analisar os resultados, episódios de ensino em que falas do professor e dos educandos são descritas, foram selecionados de modo a evidenciar as habilidades preconizadas na investigação científica. Com a análise dos resultados, é verificado que o Ensino de Ciências por Investigação é exequível na EJA, porém para que isso se torne realidade, é necessário a formação continuada e/ou parcerias entre universidades e professores da rede pública de ensino, para que através da pesquisa ou extensão resolvam juntos os problemas que permeiam a educação.

Palavras-chave: Ensino de ciências por investigação; EJA; Formação continuada.

\section{Abstract}

The official documents that establish the methodological guidelines for Youth and Adult Education (EJA) prioritize strategies that value the students' knowledge based on teaching practices permeated by dialogue. Although such guidelines exist, there seems to be a gap between them and what is experienced in schools. Such detachment is evident when faced with teachers frustrated with their practices when they realize that they do not arouse their students' interest in what they intend to teach. This work arises from a visit by two university professors to a public school to publicize a university extension project. After this first contact, a physics teacher from the college asks for help from university professors to help him make his class more attractive to his EJA class. In this way, a work was carried out between researching professors (universit) and a partner professor in order to clarify the theoretical and methodological assumptions of Science Education in EJA with the approach of Science Education through Research. A class on Refraction of Light was prepared and taught by the partner teacher using materials available at the school and changing the way the class was conducted. To analyze the results, teaching episodes in which the teacher's and students' statements are described, were selected in order to highlight the skills recommended in scientific investigation. With the analysis of the results, it is verified that the Teaching of Sciences by Research is feasible in EJA and for that to become a reality, it is necessary to continue training and / or partnerships between universities and teachers from the public education network, so that through research or extension solve together the problems that permeate education. 
Keywords: Science teaching by research; EJA; Continuing education.

\section{Resumen}

Los documentos oficiales que establecen las pautas metodológicas para la Educación de Jóvenes y Adultos (EJA) priorizan estrategias que valoran el conocimiento de los estudiantes en función de las prácticas de enseñanza impregnadas por el diálogo. Aunque existen tales pautas, parece haber una brecha entre ellas y lo que se experimenta en las escuelas. Tal desapego es evidente cuando se enfrentan a maestros frustrados con sus prácticas cuando se dan cuenta de que no despiertan el interés de sus estudiantes en lo que pretenden enseñar. Este trabajo surge de una visita de dos profesores universitarios a una escuela pública para dar a conocer un proyecto de extensión universitaria. Después de este primer contacto, un profesor de física de la universidad pide ayuda a los profesores universitarios para ayudarlo a hacer que su clase sea más atractiva para su clase EJA. De esta forma, se llevó a cabo un trabajo entre profesores investigadores (universitarios) y un profesor asociado para aclarar los supuestos teóricos y metodológicos de la educación científica en EJA con el enfoque de la educación científica a través de la investigación. El maestro asociado preparó y enseñó una clase sobre Refracción de la Luz utilizando los materiales disponibles en la escuela y cambiando la forma en que se llevó a cabo la clase. Para analizar los resultados, se seleccionaron episodios de enseñanza en los que se describen las declaraciones del profesor y de los alumnos, para resaltar las habilidades recomendadas en la investigación científica. Con el análisis de los resultados, se verifica que la Enseñanza de las Ciencias por Investigación es factible en EJA y para que eso se convierta en realidad, es necesario continuar la capacitación y / o alianzas entre universidades y docentes de la red de educación pública, de modo que a través de la investigación o extensión resuelven juntos los problemas que impregnan la educación.

Palabras clave: Enseñanza de las ciencias por investigación; EJA; Educación continua.

\section{A Educação de Jovens e Adultos no Brasil e o Ensino de Ciências}

No contexto das ações educativas de pessoas jovens e adultas no Brasil, encontra-se ações desde a época dos jesuítas no período colonial, que em caráter missionário, buscavam catequizar pessoas adultas. Legitimamente, apenas a partir da constituição de 1824, no Brasil Império, é firmada em documentos a responsabilidade do estado na educação primária e gratuita para todos os cidadãos, a qual não teve muito efeito prático por questões estruturais, entre elas, a pequena parcela da população era considerada cidadã e o ato adicional de 1834 
que destinava às províncias a responsabilidade pela educação básica, enquanto o governo imperial se responsabilizava pela educação das elites. Essas e outras questões estruturais, favorecendo sempre as elites em detrimento as camadas sociais marginalizadas, fizeram com que o Brasil chegasse em 1920, cerca de 30 anos após o estabelecimento da República no país, com 72\% da população, maior de 5 anos de idade, analfabeta (Haddad, 1987).

De acordo com o mesmo autor, vésperas ao fim da primeira Guerra Mundial, o país se encontra com altos índice de analfabetismo comparado à América Latina e ao resto do mundo. As elites brasileiras passam a ver a educação como um dever que cada brasileiro deveria assumir com a sociedade. A partir de 1930, com a reformulação do papel do serviço público no Brasil, a educação de jovens e adultos começa a ser debatida com maior ênfase e a fazer parte da legislação nacional: a constituição de 1934 reafirma o direito de todos e o dever do estado com a educação; desenvolvimento do Plano Nacional da Educação que inclui o ensino primário gratuito, de frequência obrigatória e extensiva a adultos; criação do Instituto Nacional de Estudos Pedagógicos (INEP) que em 1942 instituiu o Fundo Nacional do Ensino Primário; sobre influência da Organização das Nações Unidas para a Educação, Ciência e a Cultura (UNESCO), que denunciava as grandes desigualdades dos países pós segunda Guerra Mundial, em 1947 foi instalado o Serviço de Educação de Adultos (SEA) que se estendeu até o fim da década de 50. Todos esses esforços fizeram os índices de analfabetismo caírem para $46,7 \%$ da população maior do que 5 anos de idade.

O início da década de 60 é marcado pelo sucesso do "método Paulo Freire", mas interrompida pelo golpe militar levando ao exílio o autor do método. Entretanto a educação de jovens e adultos não pôde ser abandonada pelo estado. Durante o regime militar temos a criação do Movimento Brasileiro de Alfabetização (Mobral) em 1967 e o Ensino Supletivo em 1971 (Saraiva, 2004).

Historicamente percebe-se que a modalidade de Ensino de Jovens e Adultos (EJA) está presente no contexto da educação brasileira sob influência e interferência de forças políticas e ideológicas. Com a tomada de consciência desses fatos pesquisas começaram a ser realizadas de modo a debater o analfabetismo no Brasil como dívida cultural, social e responsabilidade de todos.

Nas últimas décadas a educação de pessoas jovens e adultas (EJA) vem adquirindo uma nova atenção, a Lei de Diretrizes e Bases Nacionais (LDB), n 9.394/96 garante a oferta de EJA como modalidade da educação básica nas etapas de ensino fundamental e médio (Brasil, 1996). O Parecer CNE/CEB 11/2000 do Ministério da Educação, que define diretrizes para EJA considerando as especificidades desta modalidade, aponta um reconhecimento dos 
direitos negados aos jovens e adultos ao longo de sua história e descaso do Estado em relação aos direitos de uma educação para todos (Brasil, 2000a).

A reflexão no ambiente escolar sobre as relações de classe social, de trabalho, de informação para alguns, não pode ser negado àqueles que foram, e são, excluídos do processo educacional, geralmente jovens e adultos trabalhadores os quais estão à margem de vários direitos fundamentais. É neste contexto que se deve abordar a educação de adolescentes, jovens e adultos numa perspectiva de eliminar a visão preconceituosa do analfabeto ou iletrado como inculto ou apto apenas para tarefas e funções ditas desqualificadas no mundo do trabalho. Assim, afirma o Conselho Nacional de Educação,

Muitos destes jovens e adultos dentro da pluralidade e diversidade de regiões do país, dentro dos mais diferentes estratos sociais, desenvolveram uma rica cultura baseada na oralidade da qual nos dão prova, entre muitos outros, a literatura de cordel, o teatro popular, o cancioneiro regional, os repentistas, as festas populares, as festas religiosas e os registros de memórias das culturas afro-brasileira e indígena. (Brasil, 2000a, p.5)

Os gestores e docentes precisam compreender as especificidades desta modalidade. A educação deve ser pautada no respeito às diferenças sociais e culturais e no compartilhamento de conhecimentos através da oralidade. A escuta dos conhecimentos prévios dos jovens e adultos parece ser o ponto de partida de qualquer metodologia de ensino que pretenda colocar em prática com esse público.

As bases legais que orientam o Ensino na referida modalidade sugerem que deve-se superar a verticalidade imposta pela organização social da instituição escola e que "todas as estratégias didático-pedagógicas, em síntese, quando adotadas criticamente, podem melhor dimensionar o fazer escolar na EJA e a participação dos educandos” (Brasil, 2008).

Ainda sobre o rompimento da verticalidade da organização escolar, Freire (1997) aponta o papel da "dialogicidade" como essência da educação como prática da liberdade. Nessa perspectiva entende-se que o educador dialógico deve ser capaz de organizar o conteúdo programático a fim de acrescentar ao educando os elementos científicos que lhes foram concebidos de forma desestruturada.

No que tange o Ensino de Ciências, há notável preocupação do ponto de vista metodológico para que a dimensão da investigação científica seja contemplada na prática escolar. Os Parâmetros Curriculares Nacionais (PCN’s) apontam a necessidade de se contemplar o método científico no conteúdo a ser ensinado. Em relação ao Ensino de Física, mais especificamente, destacam que as competências de investigação e compreensão, 
linguagem e comunicação, e contextualização histórico e social, devem ser exploradas de modo que seja possível atribuir significados aos conteúdos que se pretende ensinar, fazendo com que o as Ciências Físicas se tornem significativas aos educandos (Brasil, 2000b).

Em relação à didática do Ensino de Física, as Orientações Curriculares do Ensino Médio destacam que o professor deve ser capaz de desenvolver situações que estimulem os educandos a elaborarem hipóteses de modo a possibilitar a construção de modelos científicos através de situações problemas (Brasil, 2006).

Parece haver uma clara convergência nos documentos oficiais que regulamentam o Ensino de Ciências, seja na modalidade regular ou EJA, no que se refere ao aspecto metodológico. Neste trabalho, defende-se a hipótese que uma proposta de ensino baseada na investigação permite ao professor desenvolver a dialogicidade com o conteúdo programático da EJA, e que através de uma relação de colaboração educador e educando transformam o mundo.

Dessa maneira, foi realizado um trabalho entre professores pesquisadores (universitários) e professor parceiro (rede pública de ensino) com objetivo de esclarecer os pressupostos teóricos e metodológicos do Ensino de Ciências na EJA com a abordagem do Ensino de Ciências por Investigação. Uma aula sobre Refração da Luz foi elaborada e ministrada pelo professor parceiro utilizando materiais disponíveis na escola e alterando a maneira de condução da aula para atingir os pressupostos da investigação.

A discussão dos resultados indica que para o Ensino da Física atingir os objetivos preconizados nos documentos oficiais, seja na modalidade regular ou na EJA, é necessário que haja mudança na postura metodológica do professor e para que a dimensão da investigação seja alcançada não é necessário muito mais do que já se tem nas escolas/colégios. O que é necessário é a tomada de consciência sobre os pressupostos da investigação.

Na sequência será realizada uma breve discussão sobre o Ensino de Ciências por Investigação e seus pressupostos metodológicos dando ênfase na demonstração investigativa, a metodologia de pesquisa, os resultados e por fim, as considerações finais bem como apontamentos e sugestões de continuidade.

\section{O Ensino de Ciências por Investigação}

A elaboração de uma aula com pressupostos no ensino por investigação deve ser planejada de modo a permitir o máximo possível de participação do aluno, para que professor 
e aluno (re)construam o conhecimento. O professor deve assumir a postura de orientador oportunizando a participação dos educandos na realização das atividades e nos debates a respeito dela. $\mathrm{O}$ aluno, por sua vez, assume atitude ativa, tendo que pensar, debater, justificar suas ideias e aplicar seus conhecimentos em situações novas. A argumentação assume posição crucial nesse enfoque (Carvalho et al., 1999).

Diversos pesquisadores concordam que o ensino por investigação deve desenvolver habilidades nos alunos, tais como, a reflexão, a discussão, a explicação e a elaboração de relatos. Parece também haver um consenso sobre os momentos que uma atividade deve contemplar para que as habilidades sejam desenvolvidas, são elas: proposição de um problema, preferencialmente no formato de uma pergunta; levantamento de hipóteses; coleta de dados; análise dos dados obtidos; e conclusão, como resposta ao problema inicial (Azevedo, 2013; Gil Pérez, D. \& Valdes Castro, P., 1996; García Rodriguez, J.J \& Cañal de León, P., 1995).

Nesse sentido, acredita-se que o aspecto determinante para desenvolver o Ensino de Ciências por Investigação é planejar um ambiente em que o educando possa explorar o método científico partindo de um problema que permita o levantamento hipóteses, a testagem delas, confirmando-as ou refutando, a defesa de seu posicionamento através da argumentação, e por fim, a elaboração de uma conclusão. Nesse processo o aluno se torna ativo sendo responsável pela (re)construção do seu conhecimento e o professor é o organizador do ambiente para que isso aconteça.

Para o desenvolvimento desse trabalho foi elaborada uma aula baseada na demonstração experimental investigativa. Para Azevedo (2013), esse tipo de atividade deve partir da apresentação de um problema ou um fenômeno seguindo algumas etapas, tais como: proposição de um problema; discussão geral do problema com os alunos; demonstração; discussão do que foi observado; e explicações científicas. Além disso, o professor se torna um orientador na sala de aula, e é através da argumentação e proposição de questões, que conduz seus educandos ao levantamento de hipóteses e a darem possíveis explicações casuais acerca do fenômeno observado.

Este trabalho teve como objetivo principal instrumentalizar metodologicamente um professor de Física que atua na EJA em relação ao Ensino de Ciências por Investigação e colocá-lo numa situação de experiência. 


\section{Percurso Metodológico}

Primeiramente firmou-se uma parceria entre professores pesquisadores e um professor de Física que atua na EJA na rede pública de ensino na cidade de Rio Verde em Goiás. A parceria se deu de maneira voluntária a partir de uma visita dos professores pesquisadores no colégio onde o professor parceiro leciona, com a finalidade de apresentar um projeto de extensão universitária no segundo semestre de 2019. Na ocasião o professor parceiro pediu auxílio dos professores pesquisadores no desenvolvimento de atividades que pudessem "motivar mais os alunos" da EJA.

Diante a solicitação, os professores pesquisadores se dispuseram a ajudar o professor parceiro na elaboração e desenvolvimento de uma aula nos pressupostos do Ensino de Ciências por Investigação levando em consideração a realidade da escola e os recursos disponíveis. Para coletar dados que permitiriam descrever o perfil do professor e da turma, faz-se uma entrevista com o professor parceiro para conhecer aspectos relacionados à sua formação profissional e a realidade do seu local de trabalho, bem como os motivos que o levaram a escolher a turma na qual a atividade investigativa seria desenvolvida.

Em seguida é elaborado um roteiro de pesquisa (professores pesquisadores) dividido em três etapas, conforme a Tabela 1.

Tabela 1: Roteiro de pesquisa.

\begin{tabular}{cc}
\hline Atividade desenvolvida & Duração \\
\hline Observação de aulas & 02 semanas (04 aulas) \\
\hline Elaboração da atividade & Ao término da observação \\
\hline Execução & 1 aula (50 min) \\
\hline
\end{tabular}

Fonte: Autores (2019).

Na etapa de "observação de aulas" do professor parceiro, o objetivo foi constatar a postura da turma frente à metodologia de ensino utilizada por ele, em que os professores pesquisadores buscariam elementos que justificasse a apatia da turma que o incomodava. Já na etapa de "elaboração da atividade", professores pesquisadores apresentaram ao professor parceiro os pressupostos teóricos e metodológicos do Ensino de Ciências por Investigação e definiram que a demonstração experimental investigativa seria uma metodologia em potencial, dada a realidade local. Dessa maneira, foi elaborada uma aula sobre Refração da Luz utilizando material alternativo de fácil acesso. Por fim, na "execução", o professor 
parceiro desenvolve a aula planejada em sua turma.

A metodologia dessa pesquisa é qualitativa, visto que o ambiente natural (colégio e sala de aula) são fontes diretas de dados e o pesquisador é quem coleta dos dados que são predominantemente descritivos a partir da observação e acompanhamento das aulas do professor parceiro. O foco maior é dado ao processo (desenvolvimento/condução da aula e reação/interação dos educandos) e a análise de dados segue um processo indutivo (Ludke \& André, 1986).

Para obter dados e informações durante a execução da aula pelo professor parceiro utilizou-se como instrumento de coleta de dados uma câmera para filmar a aula, e a análise de conteúdo de Bardin (2004) foi aplicado para interpretar os dados.

A descrição analítica dos dados é realizada através da seleção de episódios de ensino em que as falas dos educandos permitiram a constatação de elementos característicos do ensino por investigação. Para facilitar a análise, as falas foram classificadas em categorias e por fim, no tratamento dos resultados, é feita uma discussão interligando os resultados obtidos com o referencial teórico.

As categorias de análise foram elaboradas de acordo com as habilidades que se pretende desenvolver no educando quando ele experimenta uma atividade investigativa. São elas: (1) reflexão, (2) discussão, (3) explicação e (4) elaboração de conclusões.

É importante deixar claro que tanto professor parceiro quanto os educandos que tem suas falas descritas, assinaram termo de esclarecimento livre e consentido. Para resguardar a privacidade dos participantes da pesquisa, serão utilizados o símbolo "P" para descrever as falas do professor e o símbolo "E" seguido de um número para identificar a fala dos educandos. Os episódios selecionados transcrevem as falas de 05 educandos com o professor. Esses episódios e educandos foram escolhidos por apresentarem alto valor de análise em relação as categorias criadas.

\section{Resultados e Discussão}

\subsection{Perfil do professor parceiro e da turma de EJA}

O professor tinha 38 anos de idade, licenciado em Matemática a 12 anos com complementação pedagógica em Física a aproximadamente 06 anos. Lecionava em colégios privados como celetista e no período dessa pesquisa trabalhava em colégios da rede estadual no regime de contrato temporário, com carga horária semanal de 52 aulas. De acordo com o 
professor não foi uma escolha lecionar na EJA, e que para complementar a carga horária descrita em seu contrato foi aconselhável que assumisse as turmas.

Cabe ressaltar que os Parâmetros Curriculares Nacionais - EJA, em sua parte introdutória, destaca que grande parte dos professores que atuam nessa modalidade de ensino têm como motivação o fato de gostar da profissão, preencher carga horária/necessidade financeira, necessidade do sistema de ensino, interesse dos alunos, para ter experiência, por terem sido convidados (Brasil, 2002). Percebe-se que o perfil do professor parceiro está de acordo com o perfil do professor da EJA diagnosticado há mais de 18 anos.

Durante a observação das aulas nota-se a preocupação do professor com o aprendizado dos educandos, se mostrando sempre prestativo e atencioso quando solicitado a tirar alguma dúvida, porém do ponto de vista de conteúdo percebe-se que há uma preocupação em resolver problemas com enfoque matemático, sobre os princípios da propagação retilínea da luz em câmaras escuras de orifício sem dar a ênfase necessária nos conceitos como, por exemplo, as consequências da propagação retilínea na formação de sombras, configurando os dias e noites, eclipses, fases da lua, etc. Embora o professor tenha complementação pedagógica em Física, sua formação inicial parece sobressair em relação à secundária, dando mais ênfase no ensino de operações matemáticas do que no ensino de conceitos e/ou fenômenos físicos.

Também fica claro a postura metodológica adotada pelo professor, uma postura bem tradicional, onde ele apresenta os conceitos e formulações matemáticas sem evidenciar as concepções prévias dos educandos. Cabe ressaltar que:

Ao trazer para a sala de aula a realidade vivida pelos alunos, os mesmos se sentem instigados, participam das aulas com mais motivação e vão, aos poucos, expondo suas experiências de vida para resolver as questões apresentadas. Essa atitude levanta a autoestima dos alunos e contribui para uma melhor apreensão dos conhecimentos (Augustinho, 2010, p. 25).

Ainda para a autora, o ensino de Ciências na EJA deve contemplar e explorar atividades experimentais, pois seu caráter lúdico e motivador, desperta um forte interesse nos educandos. A experimentação não deve ser desenvolvida numa visão positivista, mas sim ser explorada considerando "às possibilidades de erro e acerto como estratégia de ensino para resolução de problemas" (Augustinho, 2010).

Questionado sobre a turma em que ele desejaria desenvolver a atividade, ele ressalta que a escolha se deu pelo fato de a turma ser apática nas aulas, mas que ele percebe que existe 
motivação por parte dos educandos, ocasionando nele um sentimento de frustração por não atingir as expectativas de seus educandos.

A turma escolhida pelo professor era noturna e constituída por 18 educandos frequentes, sendo 12 mulheres e 06 homens, com idades entre 22 e 56 anos. Do total, 03 se declaram desempregados no momento, e todos pensavam em terminar a EJA para ingressarem na universidade.

Nota-se um perfil heterogêneo na turma, o que reforça a necessidade do desenvolvimento de estratégias de ensino que considerem os saberes desses aprendizes e que possibilite uma aprendizagem compartilhada entre seus pares, visto que a diferença de idades é uma característica marcante no grupo em questão. Sampaio (2010) destaca a importância de metodologias que permitam trabalhar com as diferenças, ou seja, propostas em que os diferentes possam interagir e que os sujeitos nas suas diferenças aprendam uns com os outros. Defende-se aqui, que o Ensino de Física por Investigação pode além de desconstruir a passividade dos educandos, queixada pelo professor, pode também dar voz fazendo com que eles se sintam responsáveis pelo processo de ensino e aprendizagem.

Durante a observação das aulas não é evidenciada a apatia, no sentido de não participarem da aula, como queixada pelo professor. Na verdade, o que foi observado é que o único momento em que os educandos têm oportunidade de expressarem seus sentimentos e participarem da aula é na resolução de exercícios. Nesses momentos, foi possível perceber várias queixas por parte educandos relacionados à dificuldade em operações matemáticas na resolução de problemas físicos. Tais como:

\section{E3 ${ }^{1}$ : “_Professor eu não entendi nadinha de nada. Qual é a fórmula? E6: “_Ah não professor. Eu desisto! Eu não sei nem por onde começar.}

A partir das observações das aulas, da realidade e perfil do professor, dos recursos disponíveis no colégio (ausência de laboratório), do perfil da turma, o professor pesquisador apresenta para o professor parceiro os pressupostos da investigação no Ensino de Ciências e como seria uma aula de demonstração experimental investigativa.

\footnotetext{
${ }^{1} \mathrm{O}$ símbolo " $E$ ” está sendo utilizado para representar a transcrição das falas dos educandos(as) e o número para diferenciá-los.
} 
Nesse momento, fica claro para o professor parceiro que para desenvolver uma aula nessa perspectiva, não há necessidade de aparato experimental sofisticado, que demandaria muito tempo para preparação. Acredita-se que uma vez, que o professor tenha consciência de que é possível desenvolver a investigação na sala de aula, com os recursos disponíveis ou com materiais alternativos de fácil acesso, e que o principal foco é a mudança na forma de conduzir a aula, através de questionamentos problematizadores, debates, discussão, muito se ganha no processo de ensino e aprendizagem em Ciências, principalmente na EJA, pois os educandos trazem muito conhecimento de suas experiências e vivências.

\subsection{A aula: Refração da luz através de uma demonstração experimental investigativa}

$\mathrm{Na}$ perspectiva experimental tradicional, o professor, além de manipular o experimento, ele também explica o fenômeno demonstrado sem dar condições ou o tempo suficiente para que os educandos reflitam sobre os acontecimentos. Já na perspectiva investigativa, o fenômeno evidenciado no experimento manipulado pelo professor, deve ser explicado pelos educandos a partir de suas observações e conhecimentos prévios. A troca de saberes entre os pares deve ser capaz de conduzir a elaboração de hipóteses, e o professor deve estar atento para mediar a construção do conhecimento utilizando-se de sua experiência para isso.

Para a aula, o problema gerador era sobre a utilização dos sentidos humanos para mensurar grandezas físicas como temperatura, por exemplo. Na sequência, o professor apresentaria uma atividade de demonstração investigativa para explorar a confiança dos educandos em relação a visão para explorar o conceito de Refração da Luz. A atividade consiste em colocar um lápis em dois copos transparentes e em um dos copos despejar água, como pode ser visto na Figura 1. 
Figura 1: Atividade de Refração da Luz.

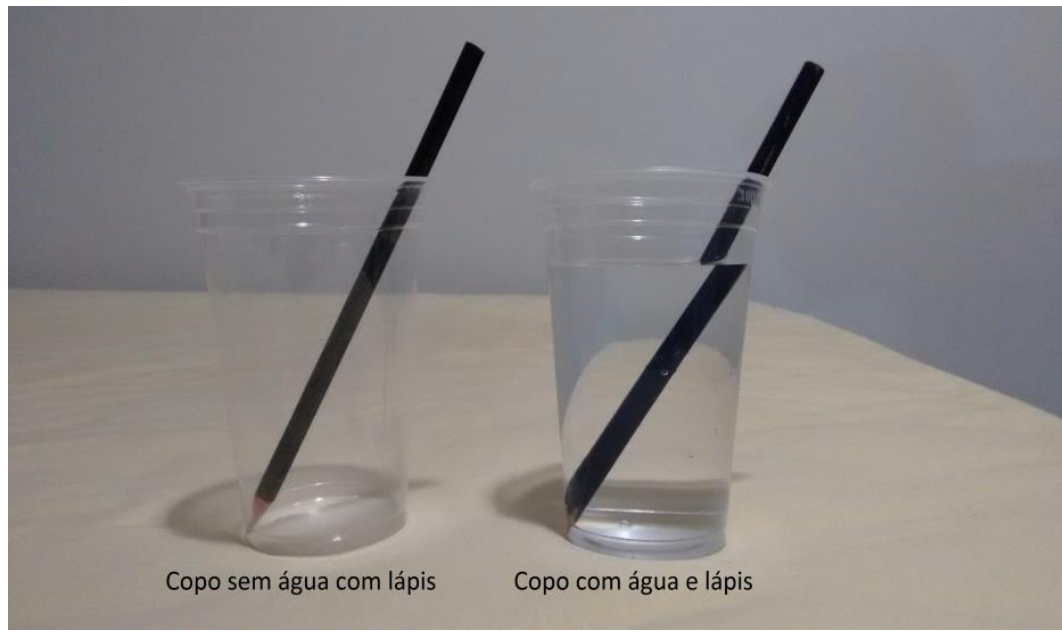

Fonte: Autores (2019).

$\mathrm{Na}$ seção seguinte é realizado a análise da aula. As falas foram transcritas e classificadas em categorias para facilitar a análise e discussão. O símbolo P se refere a fala do professor e o símbolo E seguido de um número se refere a fala de um educando. As categorias de análise estão enumeradas de 1 a 4 conforme o Quadro 1.

Quadro 1: Categorias de análise.

\begin{tabular}{|c|c|c|}
\hline Categoria & Tipo & Descrição \\
\hline 1 & Reflexão & Apreciação de situação(ões) que pode(m) ter(em) ou não relação \\
com o problema proposto.
\end{tabular}

Fonte: Autores (2019).

\subsection{A construção do conhecimento a partir do problema e da discussão}

A aula é iniciada com um debate sobre os sentidos humanos. Esse debate foi pensado a fim de levantar alguns elementos para dar significado à aula. Cabe ressaltar que conceitos de 
temperatura e calor já haviam sido trabalhados na turma. O Quadro 2 descreve o primeiro episódio que será analisado a partir das categorias.

Quadro 2: Episódio 1 da aula sobre refração.

\begin{tabular}{|c|c|c|}
\hline Turno & Falas transcritas & $\begin{array}{r}\text { Categoria } \\
\text { evidenciada }\end{array}$ \\
\hline 37 & $\begin{array}{l}\mathrm{P}^{2}: \text { "hoje iremos realizar duas atividades bem simples com o } \\
\text { objetivo de responder a questão... será que podemos confiar em } \\
\text { nossos sentidos?" }\end{array}$ & \\
\hline 38 & E2: “não...” & \\
\hline 39 & P: "nós temos cinco sentidos... não são? Quais são eles?" & \\
\hline 40 & TODOS: "visão... audição... tato... olfato... paladar..." & \\
\hline 50 & $\begin{array}{l}\text { P: "isso... são os cinco sentidos que temos... sempre os usamos... } \\
\text { por exemplo... quem nunca mediu a febre de uma criança } \\
\text { colocando a mão no corpo da criança? Quem nunca fez isso?" }\end{array}$ & 2 \\
\hline 51 & E3: “eu não porque minha mão me engana...” & 2 e 3 \\
\hline 52 & P: "como assim? Por que suas mãos te enganam?" & 2 \\
\hline 53 & E3: "minha mão não é muito quente?" & 1 e 2 \\
\hline 54 & E2: "pelos lábios...professor..." & 3 e 2 \\
\hline 55 & $\begin{array}{l}\text { E1: "eu fazia com as mãos mesmo... se eu visse que estava quente } \\
\text { eu ia e pegava o termômetro..." }\end{array}$ & 1 e 2 \\
\hline
\end{tabular}

Fonte: Autores (2019).

No episódio ${ }^{3} 01$ verifica-se uma mudança na forma de como o professor inicia a aula. É proposto um problema e a discussão é alimentada através de pequenos questionamentos, na tentativa de fazer com que os educandos se tornem protagonistas da situação e que se sintam à vontade em participarem da discussão. O objetivo do professor nesse momento é promover a reflexão nos educandos sobre suas ações cotidianas e que a partir daí tomem consciência de seus atos.

A situação problema deve ter relação com as vivências e experiências dos educandos, daí a importância do professor que atua nessa modalidade conhecer a história de vida de seus educandos. Sabendo que a maioria dos educandos eram pais, o problema em questão teria alto potencial para promover a dialogicidade, ou seja, fazer uma transposição do conhecimento adquirido de maneira não formal, para o conhecimento mais estruturado cientificamente.

Nos turnos ${ }^{4} 51$ e 53, nota-se que E3 dá uma explicação ao problema proposto e em seguida, por intervenção do professor, ele começa a refletir sobre sua explicação. O educando tem clareza que a sua mão não pode ser usada como instrumento de medida da temperatura.

\footnotetext{
2 O símbolo "P" se refere a transcrição da fala do professor parceiro.

${ }^{3}$ Episódio é a coleção turnos que permite evidenciar elementos da investigação.

${ }^{4}$ Turno se refere a fala individual que pode conter elementos da investigação ou dar continuidade a um episódio.
} 
Percebe-se que E1, no turno 55, aponta uma reflexão um tanto contraditória em relação a E3, evidenciando que os saberes e concepções prévias são individuais e tem relação com a trajetória de cada um.

Embora a discussão inicial proposta pelo professor não seja o foco da aula, já é possível identifica as habilidades que o ensino investigativo preconiza nesse episódio e que isso foi possível devido a mudança de postura do professor ao iniciar a aula. Durante as observações realizadas foi verificado que o professor não tinha o hábito de iniciar a aula com questionamentos, mas sim com a apresentação de conceitos e formulações matemáticas. Cabe ressaltar que um dos desafios as serem superados na EJA é exatamente a mudança nas estratégias pedagógicas dos professores que atuam na modalidade, pois dessa maneira, "todas as estratégias didático-pedagógicas, em síntese, quando adotadas criticamente, podem melhor dimensionar o fazer escolar na EJA e a participação dos estudantes” (Brasil, 2008).

Após essa discussão inicial, sobre a confiança nos sentidos humanos, o professor retoma o problema do turno 37 e reformula o problema de modo a começar a desenvolver o objetivo da aula. Dois educandos que usavam óculos (E4 e E3) afirmaram que não podiam confiar pelo fato de terem miopia e outro estrabismo, segundo eles.

Ao mesmo tempo, o professor realiza a atividade ilustrada na Figura 01 e pede aos educandos que observem os materiais utilizados solicitando que eles descrevam o que se observa enquanto água é despejada em um dos copos. No Quadro 3 será descrita as falas desse episódio. 
Quadro 3: Episódio 2 da aula sobre refração.

\begin{tabular}{|c|c|c|}
\hline Turno & Falas Transcritas & $\begin{array}{c}\text { Categoria } \\
\text { evidenciada }\end{array}$ \\
\hline 70 & $\begin{array}{l}\text { P: "tem diferença no lápis no copo com água em relação ao copo } \\
\text { sem água?" }\end{array}$ & \\
\hline 71 & TODOS: "sim..." & \\
\hline 72 & P: "qual diferença?" & \\
\hline 73 & $\begin{array}{l}\text { E3: "o copo que tem água... dá a impressão de que o lápis está } \\
\text { mais grosso... e de acordo com o que eu vou mexendo com ele } \\
\text { aqui... ele vai ficando diferente..." }\end{array}$ & 1 e 2 \\
\hline 74 & P: "e o que os outros acham?" & 2 \\
\hline 75 & E2: “dá a impressão de que ele está torto...” & $1 \mathrm{e} 2$ \\
\hline 76 & E5: "é isso mesmo..." & 2 \\
\hline 77 & P: “agora a pergunta é... por que vocês estão enxergando o lápis?” & 2 \\
\hline 78 & E5: “porque a água é transparente...” & 1,2 e 3 \\
\hline 79 & E4: "e o copo também..." & 2 e 3 \\
\hline 80 & $\begin{array}{l}\text { P: "a água é transparente... o copo também é transparente... e o } \\
\text { que mais possibilita que vocês enxerguem o lápis?" }\end{array}$ & 2 \\
\hline 81 & E5: "por causa da claridade da luz?" & 1,2 e 3 \\
\hline 82 & $\begin{array}{l}\text { P: "vocês só enxergam o lápis porque tem luz... mas o que } \\
\text { acontece com a luz e o lápis para enxergarmos ele? }\end{array}$ & \\
\hline 83 & E3: "porque a luz reflete ele..." & 2 e 3 \\
\hline 84 & $\begin{array}{l}\text { P: "é a luz refletida pelo lápis que nos possibilita enxergá-lo... } \\
\text { muito bem..." }\end{array}$ & 2 \\
\hline 85 & E3: "se você mexer a água o lápis não fica grosso?" & 1 e 2 \\
\hline
\end{tabular}

Fonte: Autores (2019).

Para Carvalho (2013), um dos principais desafios para o professor em uma atividade investigativa é consolidar um ambiente que oportunize aos educandos o levantamento de hipóteses através da observação do experimento e de pequenos questionamentos, para que passem da ação manipulativa à intelectual mediada pela argumentação entre colegas e professor. Nota-se no episódio 02, que o professor desenvolveu papel fundamental no desenvolvimento da discussão, conseguindo fazer com que os educandos explicassem suas observações baseadas na atividade de demonstração (turnos 78, 81 e 83). Ele ainda se mostrou atento para promover mudança conceitual quando foi necessário (turno 84). Cabe ressaltar que as leis da reflexão já haviam sido estudadas em aulas anteriores, demonstrando ainda um problema na consolidação desses conceitos.

Os turnos 73 e 85 evidenciam que a atividade proposta foi capaz de explorar as habilidades de observação e verificação de regularidades físicas, que são orientações preconizadas nos Parâmetros Curriculares da EJA (Brasil, 2002). O E3 observou que a espessura do lápis, algo que não havia sido considerado nas falas do professor, estava 
diferente. Nota-se curiosidade e interesse do educando pela atividade proposta. O professor solicita a ajuda dos colegas para investigarem a observação feita por E3.

Após a realização da demonstração a aula foi conduzida de modo que os educandos elaborassem explicações acerca do fenômeno observado. Neste momento parecia estar claro para todos que o fato de enxergar o lápis é pelo fato dele refletir a luz que incide nele. Quando os educandos são colocados numa situação de elaboração de explicações em relação ao que foi observado, ou seja, o fato de o lápis parecer "grosso e torto" dentro da água, percebe-se que os educandos se mostram ativos, como pode ser observado no episódio 04.

Quadro 4: Episódio 3 da aula sobre refração.

\begin{tabular}{|c|c|c|}
\hline Turno & Falas transcritas & $\begin{array}{c}\text { Categorias } \\
\text { evidenciadas }\end{array}$ \\
\hline 96 & $\begin{array}{l}\text { P: “...atravessa a água... mas sem a água a gente enxerga o lápis } \\
\text { como se nada tivesse acontecido... com a água nós estamos } \\
\text { enxergando o lápis diferente... será que a água faz alguma coisa } \\
\text { com a luz?" }\end{array}$ & 2 \\
\hline 97 & E3: "potencializa a luz..." & $1 \mathrm{e} 2$ \\
\hline 98 & E5: “ela expande..." & $1 \mathrm{e} 2$ \\
\hline 99 & $\begin{array}{l}\text { P: "potencializa... o que mais? Eu quero mais palpites..." [Todos } \\
\text { ficam em silêncio]. }\end{array}$ & 2 \\
\hline 100 & P: "E5 você está falando que expande... por quê?" & 2 \\
\hline 101 & $\begin{array}{l}\text { E3: "potencializa... porque ela é transparente e retém a } \\
\text { claridade... aí ela reflete o objeto como se fosse um espelho..." }\end{array}$ & 1,2 e 3 \\
\hline
\end{tabular}

Fonte: Autores (2019).

Nos turnos 97 e 98, E3 e E5 ao respondem o questionamento do professor, acreditase estar havendo reflexão sobre o fenômeno, porém não foram capazes de explicar os termos utilizados. Na tentativa de compreensão dos termos, o professor questiona-os mantendo o diálogo. Nota-se que pelo fato de E3 (turno 73) ter observado que a espessura do lápis apresentava ser maior dentro da água, induziu os outros colegas a se posicionarem em relação a esse fenômeno. Os termos expandir e potencializar são palavras que remetem ao aumento de dimensão observada.

O professor, até mesmo pelo fato de não ter domínio da metodologia, não conseguiu argumentar no sentido de desconstruir o que estava sendo proposto como explicação pelos educandos e nem mesmo percebeu que o fato do lápis aparentar mais espesso dentro da água era pelo fato de o copo ser cilíndrico, ocasionando o efeito de lente, o que poderia ser usado para alimentar uma discussão com aqueles educandos que mencionaram usar óculos. 
Research, Society and Development, v. 9, n. 8, e970986707, 2020

(CC BY 4.0) | ISSN 2525-3409 | DOI: http://dx.doi.org/10.33448/rsd-v9i8.6707

É importante ressaltar que o professor deve estar muito bem preparado tanto teoricamente quanto metodologicamente, para que possa guiar as atividades sem interferir de forma a prejudicar a construção do conhecimento pelo aluno e aproveitar ao máximo as potencialidades da mesma (Azevedo, 2013, p.25). Porém se tem clareza que essa habilidade por parte do professor vai se adquirindo com a experiência e com a pesquisa.

No turno 101, E3 percebendo a insatisfação do professor, tenta dar uma explicação para sua hipótese, se mostrando perseverante em relação à atividade. Vendo que, os educandos não levantam hipóteses relacionadas à velocidade da luz, o professor começa elucidar o fenômeno da Refração da Luz com uma analogia sobre o movimento de corpos dentro da água, como pode ser visto no Quadro 5.

Quadro 5: Episódio 04 da aula sobre refração.

\begin{tabular}{|c|c|c|}
\hline Turno & Falas transcritas & $\begin{array}{c}\text { Categoria } \\
\text { evidenciada }\end{array}$ \\
\hline 126 & $\begin{array}{l}\text { E5: “como assim professor? Fica mais lento lá dentro?" [se } \\
\text { referindo à água] }\end{array}$ & 1 e 2 \\
\hline 127 & $\begin{array}{l}\text { P: “isso... olha só o que a E1 falou... está correto... é como se a luz } \\
\text { propagasse mais devagar na água... mas... por que ela vai se } \\
\text { propagar mais devagar na água?" }\end{array}$ & 2 \\
\hline 128 & E5: "porque a água meio que bloqueia ela... né?" & 2 e 3 \\
\hline 129 & $\begin{array}{l}\text { P: "olha... a água meio que bloqueia ela... vamos pensar... a luz } \\
\text { aqui na sala... está se propagando onde?" }\end{array}$ & 2 \\
\hline 130 & E5: "no ar..." & $1 \mathrm{e} 2$ \\
\hline 131 & $\begin{array}{l}\text { P: "e quando eu coloquei água no copo a luz precisa se propagar } \\
\text { onde?" }\end{array}$ & 2 \\
\hline 132 & E5: "na água..." & 1 e 2 \\
\hline 133 & P: "existe diferença entre água e ar?" & 2 \\
\hline 134 & E5: "bastante..." & 4 \\
\hline
\end{tabular}

Fonte: Autores (2019).

No episódio 04, E5 se mostra curioso (turno 126), faz o levantamento de hipótese (turno 128) e chega a pequenas conclusões. Tal episódio retrata a organização do conhecimento por E5. A analogia sobre o movimento de corpos na água e a maneira como o professor desenvolve a discussão conduz para organização do conhecimento fazendo a atingir a habilidade de conclusão, embora ainda de maneira sutil.

Mais uma vez evidencia-se o quanto a postura do professor é fundamental para despertar e desenvolver nos educandos as habilidades investigativas. Ainda de acordo com Sasseron (2016), as atividades desenvolvidas baseadas nos pressupostos do ensino por investigação devem ser planejadas de modo a permitir o máximo possível de participação do 
aluno, para que professor e aluno (re)construam o conhecimento. Segundo a autora o professor deve planejar e oportunizar a participação dos alunos na realização das atividades e nos debates a respeito dela, ou seja, o professor é orientador do processo. O aluno por sua vez assume uma atitude ativa, tendo que pensar, debater, justificar suas ideias e aplicar seus conhecimentos em situações novas. A argumentação assume posição crucial nesse enfoque.

O professor tenta manter a discussão no intuito de despertar a participação dos demais educandos. Não tendo sucesso, o educador apresenta o conceito de refração sendo a mudança na velocidade da luz quando ela atravessa meios homogêneos e transparentes. No Quadro 6, E5 continua tentando compreender o conceito.

Quadro 6: Episódio 05 da aula sobre refração.

\begin{tabular}{|l|l|c|}
\hline Turno & \multicolumn{1}{|c|}{ Falas transcritas } & $\begin{array}{c}\text { Categoria } \\
\text { evidenciada }\end{array}$ \\
\hline 149 & $\begin{array}{l}\text { E5: “quando que acontece a refração da luz? Quando a luz } \\
\text { tem um certo bloqueio?" }\end{array}$ & 1,2 e 3 \\
\hline 150 & P: “e esse bloqueio se dá devido ao quê?” & 2 \\
\hline 151 & $\begin{array}{l}\text { E5: "pode ser a água... pode ser a mesa... o que estiver } \\
\text { bloqueando... um objeto...” }\end{array}$ & 4 \\
\hline
\end{tabular}

Fonte: Autores (2019).

Nos episódios 04 e 05, verifica-se que engajamento de E5 na tentativa de compreender o fenômeno e o esforço do professor em fazer com que o educando construa sua própria conclusão acerca do fenômeno, o que foi atingido no turno 151. Quando é usado o termo "bloqueando" por E5 acredita-se que houve a elaboração e compreensão do conceito de refração da luz, associando com a diminuição da velocidade da luz ao atravessar a água.

A essa altura fica claro que a atividade proposta pelo professor atingiu o objetivo de uma atividade de demonstração investigativa, ou seja, o ambiente criado e desenvolvido pelo professor oportunizou que aos educandos o levantamento de hipóteses e estimulou, através da observação do experimento e de pequenos questionamentos, que os educandos passassem da ação observacional à intelectual mediada pela argumentação entre colegas e professor (Carvalho, 2013).

O episódio do Quadro 7, é caracterizado pela curiosidade dos educandos ao tentarem entender o fenômeno buscando por mais aplicações. 
Quadro 7: Episódio 6 da aula sobre refração.

\begin{tabular}{|l|l|c|}
\hline Turno & \multicolumn{1}{|c|}{ Falas transcritas } & $\begin{array}{c}\text { Categoria } \\
\text { evidenciada }\end{array}$ \\
\hline 157 & E5: "professor... dá um outro exemplo de refração...” & 2 \\
\hline 158 & $\begin{array}{l}\text { P: "vocês já viram um arco-íris... o arco-íris é um dos fenômenos } \\
\text { ópticos que mais chama atenção das crianças e até mesmo dos } \\
\text { adultos... mas... como que acontece um arco íris? Vamos levantar } \\
\text { os elementos necessários para a forma um arco-íris? }\end{array}$ & 2 \\
\hline 159 & E2: “devido o sol...” & 2 e 4 \\
\hline 160 & P: "mais o quê?” & 2 \\
\hline 161 & E3: "gás da atmosfera...” & 2 e 4 \\
\hline 162 & E5: "partículas de água...” & 2 \\
\hline 163 & $\begin{array}{l}\text { P: "ótimo... obrigatoriamente precisa ter luz... o sol... e precisa ter } \\
\text { partículas de água... quando a luz do sol passa pelas gotículas de } \\
\text { água que ficou na atmosfera o que vai acontecer com a luz? }\end{array}$ & \\
\hline 164 & E5: "ela vai mudar de direção...” & 2 e 4 \\
\hline
\end{tabular}

Fonte: Autores (2019).

A contextualização é fundamental numa atividade de caráter investigativo. Fica evidente que houve uma mudança de postura e de atitudes em E5, e que isso se deu devido à mudança na maneira de como o professor conduziu a aula, fazendo com que o educando assumisse uma postura ativa durante a aula (turno 157).

No episódio 06 nota-se que há compreensão do fenômeno por um número maior de educandos, mostrando que houve compreensão de que para ocorrer a refração da luz há necessidade que ela atravesse um meio transparente, como citados nos turnos 161 e 162, e também houve compreensão de que uma das consequências da refração luz pode ser identificada pelo seu desvio (turno 164).

A partir desse momento o professor escreve o conceito de Refração da Luz na lousa e explica a Lei de Snell-Descartes. Como o objetivo desse trabalho foi avaliar o potencial da atividade de demonstração investigativa no desenvolvimento de habilidades inerentes à investigação, o restante da aula não será detalhado.

Ao longo dos episódios descritos, nota-se que uma pequena mudança na maneira do professor iniciar a aula foi favorável para o desenvolvimento de habilidades preconizadas nos pressupostos do Ensino de Ciências por Investigação e estão em consonância com os pressupostos da EJA. Com uma atividade experimental demonstrativa considerada simples, do ponto de vista que os materiais utilizados, são acessíveis a qualquer professor e a qualquer escola, foi possível desenvolver um ambiente de aprendizagem em que os sujeitos se tornaram ativos e participantes do processo de ensino. 
É perceptível a dificuldade do professor em desenvolver uma discussão que favoreça a construção do conhecimento por parte dos educandos sem que ele dê a resposta como algo pronta e acabada. Mas acredita-se que essa habilidade por parte do professor vai se adquirindo com a experiência em atividades com esse enfoque metodológico. De acordo com França \& Barcelos (2020), uma das maiores dificuldades ao se propor atividades investigativas é mudança atitudinal do corpo docente que se encontram "acostumados" a desenvolverem metodologias de ensino que não geram reflexão. Neste trabalho destacamos a disposição e a busca do professor por algo que poderia melhorar sua prática pedagógica na Educação de Jovens e Adultos.

\section{Considerações Finais}

Ao longo do processo dessa pesquisa, nota-se que existe um distanciamento em relação às orientações oficiais e ao que se é praticado na sala de aula da EJA. Acredita-se que esse distanciamento se deve a falta de clareza das especificidades dessa modalidade de ensino por parte dos professores que nela atuam.

Nesse sentido, o objetivo principal desse trabalho foi $o$ de instrumentalizar metodologicamente um professor de Física que atua na EJA em relação ao Ensino de Ciências por Investigação e colocá-lo numa situação de experiência. Com isso, verificou-se que o ensino no viés da investigação é passível de ser desenvolvido na referida modalidade de ensino, utilizando das ferramentas disponíveis nas escolas sem necessidade de aquisição de laboratórios sofisticados.

Cabe ressaltar, que o ensino de Física na perspectiva da investigação traz em sua fundamentação teórica as bases e pressupostos, seja para qual for a modalidade de ensino, atinja seus objetivos. Com a análise dos episódios, verificou-se que, mesmo o professor não tendo domínio total da técnica, uma atividade de demonstração e a mudança na maneira de conduzir a aula, em que a discussão como elemento primordial na construção do conhecimento foi enfatizada, possibilitou a evidenciação de habilidades inerentes a investigação nos educandos.

Em relação a formação do professor, salienta-se que o mesmo passou por dois cursos de licenciatura e, mesmo assim, demonstra limitações em relação às metodologias de ensino de Física enfatizando a linguagem matemática que faz com que o público da EJA demonstre desmotivação em relação a disciplina. Isso reforça a necessidade de cursos de formação 
continuada para os que os profissionais da educação principalmente no que se refere as práticas metodológicas.

Por fim, destaca-se a importância do contato entre a universidade e comunidade que possibilita o diálogo entre colegas de profissão na tentativa de resolverem um problema que, embora muito discutido nas licenciaturas, ainda parece ser um obstáculo no "chão da escola", que é a falta de significação dos conteúdos curriculares. É necessário fortalecer os laços entre universidade e comunidade, pois a partir dessa aproximação e da troca de experiências, vários problemas poderão ser resolvidos.

\section{Referências}

Azevedo, M. C. S.(2013). Ensino por Investigação: Problematizando as atividades em sala de aula. In: Carvalho, A. M. P. (org). Ensino de Ciências: Unindo a Pesquisa e a Prática. Cap.2, 19-33, São Paulo: Cengage Learning.

Agustinho, E. (2010) O Ensino de Ciências na educação de jovens e adultos: uma avaliação nas escolas da baixada fluminense. 129 f. Dissertação (Mestrado Profissional em Ensino de Ciências). Instituto Federal de Educação, Ciência e Tecnologia do Rio de Janeiro, Nilópolis. Bardin, L. (2004) Análise de Conteúdo. (3a ed.), Lisboa: Edições 70.

Brasil. (1996). Lei de diretrizes e bases da educação nacional. Brasília DF: Presidência da casa Civil

Brasil. (2000a). Parecer CNE 11/2000: Diretrizes Curriculares Nacionais para a Educação de Jovens e Adultos. Brasília DF: Câmara de Educação Básica.

Brasil. (2000b). Parâmetros Curriculares Nacionais (Ensino Médio). Brasília DF: Secretaria de Educação Média e Tecnológica.

Brasil. (2002). Proposta Curricular para a Educação de Jovens e Adultos: segundo seguimento do ensino fundamental: $5^{\mathrm{a}}$ a $8^{\mathrm{a}}$ série. Brasília DF: Secretaria de Educação Fundamental.

Brasil. (2006). Orientações Curriculares para o Ensino Médio. Brasília DF: Secretara de Educação Básica. 
Brasil. (2008). Desafios da Educação de Jovens e Adultos no Brasil: Documento Base Nacional. Brasília DF: Secretaria de Educação Continuada, Alfabetização e Diversidade.

Carvalho, A. M. P., de et al (1999). Termodinâmica: um ensino por investigação. São Paulo: FEUSP.

Cavalho, A. M. P. (2013) O ensino de Ciências e a proposição de sequências de ensino investigativas. In: Carvalho, A. M. P. de (Org.). Ensino de Ciências por investigação: Condições para implementação em sala de aula. São Paulo: Cengage Learning, 1-20.

França, C. O. G., \& Barcellos, M. E. (2020). Generative theme, thematic investigation and approach: a literature panorama. Research, Society and Development, 9(7), 1-27, e145974126. DOI: http://dx.doi.org/10.33448/rsd-v9i7.4126

Freire, P. (1997). Pedagogia da autonomia. (6a ed.), Rio de Janeiro: Paz e Terra.

Gil Pérez, D. \& Valdes Castro, P. (1996). La orientación de lãs practices de laboratorio como investigacíon: um ejemplo ilustrativo. Enseñanza de las ciencias, 14 (2), 155-163.

García Rodriguez, J. J., \& Cañal de León, P. (1995). Como enseñar? Hacia una definicíon de las estratégias de enseñanza por investigacíon. Investigacíon em La escuela, 25,5-16.

Haddad, S. (Coord.) (1987). Ensino supletivo no Brasil: o estado da arte. Brasília: Inep, Reduc.

Ludke, M., \& André, M. E. D. A. (1986) Pesquisa em Educação: abordagens qualitativas. São Paulo, EPU.

Sampaio, M. N. (2010). Diferenças e prática pedagógica na EJA. Anais... In: XV ENDIPE Encontro Nacional de Didática e Prática de Ensino, Belo Horizonte. Anais. Belo Horizonte.

Saraiva, I. S. (2004). Educação de jovens e adultos: dialogando sobre aprender e ensinar. Passo Fundo: UFP. 
Sasseron, L. H. (2016). Interações discursivas e investigação em sala de aula: o papel do professor In. Carvalho, A. M. P. (org). Ensino de ciências por investigação: condições para implementação em sala de aula. Cap. 3, 41-62. São Paulo: Cengage Learning.

\section{Porcentagem de contribuição de cada autor no manuscrito}

Milton Batista Ferreira Junior - 50\%

Vinícius Alexandre de Castro - 25\%

Michael Dowglas de Gois Silva - 25\% 